of life, the age of the gods, the four quarters in heaven and earth, the immortal gods, and other high matters from peoples all over the world and from savage or barbarian conditions to the high cultures of the East, all of which originally were derived from Egypt. Even in Egypt no fundamental advance was made after the formulation of the propositions of the pyramid texts. Later developments in Egyptian theology consist of an elaboration of ideas already in circulation, but even with this apparent paucity of invention in later times, Egyptian religious thought seems to have dominated that of other peoples throughout the ages.
The activities of mankind are usually dominated by tradition, and this preserves the continuity of social institutions; but it does not occur to mankind as a whole to inquire into the reasons for social institutions, even when they are disassociated from practical utility or operate to the detriment of many members of the community. Tradition often blinds men to the obvious, and perverts their intelligence. Perhaps Dr. Perry has some excuse in adding that even scientific views are often accepted because they come from a trusted source, and it requires a stubborn spirit to maintain intellectual integrity.

\section{A. C. HadDon.}

\title{
Non-Religion of the Future
}

Psychology and Religion:

a Study by a Medical Psychologist. By Dr. David Forsyth. Pp. ix +221 . (London: Watts and Co., 1935.) 7s. $6 d$. net.

THE opinions of a distinguished psychiatrist upon the relations of psychology and religion are of great interest and importance. Dr. Forsyth's views are quite definite: religion and science, whether psychological or other, are quite incompatible with one another, because they involve two entirely different points of view. Religion is based on 'pleasure thinking', that is, on fantasy, while science is based on 'reality thinking'. Religion in short is concerned with illusions and not with reality, and belongs, properly speaking, to the infancy of our race, and not to its maturity, and so 'should be superseded in the present stage of civilisation'.

Dr. Forsyth holds that much of the imaginative power of individuals is at present wasted in the unprofitable 'pleasure thinking' associated with religion, and that if it were not dissipated in this way, but 'purposely linked to science', it might be far more beneficial to humanity. Though at the same time he would allow this imaginative power, as at present, to be devoted to the creative arts. "Science alone does not fully satisfy, and few are not the happier and better by turning from it at times, to passively enjoy the creative activities of others in books, music, and other forms of art".

It is to be doubted whether artists and those seriously interested in their work would agree to this relegation of art to the status of a recreation provider for tired men of science and professional or business men. The artist, no less than the scientific student, regards himself as establishing contact with truth; his primary function is not to amuse people, but to enlarge their perceptions of reality.

Dr. Forsyth raises many interesting questions, and is perhaps on occasion too optimistic about the benefits that science is likely to bestow. It is indeed true that a world wholly guided by science would be "free from intolerance such as has marred the old religions". But when will the world be so guided, and not by the economic and political prejudices which have displaced religious? It is a bad sign that though religion has declined, intolerance in Europe has increased.

Dr. Forsyth adumbrates the revolutionising not only of our educational system, but also of the relations of parents and children, by the new psychological knowledge. The patriarchal basis of our culture does indeed seem to be giving way. Dr. Forsyth is no sentimentalist, and it would have been interesting to hear from him what is the particular neurosis lurking behind the unbalanced child-worship which has now become common. Is it failure to face the problems of maturity, and a consequent flight back to childhood?

Quite half of Dr. Forsyth's book is taken up with an examination of the relations between traditional Christianity and science. His analysis, both historical and psychological, is certainly very damaging to the traditional position. But is religion necessarily to be identified with a supernatural revelation, any more than art or science --which in primitive times were both regarded in that light, but are so no longer ? And cannot psychology be used to 'debunk' science and art as well as religion?

But these are big questions. Within the limits he has set himself, Dr. Forsyth has written a very useful book. 